\title{
Debi-Sürek Eğrisi Yardımıyla Taban Akımının Hesaplaması: Samsun Kürtün Irmağı Örneği
}

\author{
Vahdettin Demir $^{1 *}$, Aziz Uğur Tona ${ }^{2}$ \\ 1* KTO Karatay Üniversitesi, Mühendislik Fakültesi, İnşaat Mühendisliği Bölümü, Konya, Türkiye (ORCID: 0000-0002-6590-5658), vahdettin.demir@karatay.edu.tr \\ 2 Ondokuzmayıs Üniversitesi, Mühendislik Fakültesi, Harita Mühendisliği Bölümü, Samsun, Türkiye (ORCID: 0000-0001-7367-7731), azizugur.tona@omu.edu.tr
}

(2nd International Conference on Access to Recent Advances in Engineering and Digitalization (ARACONF)-10-12 March 2021)

(DOI: $10.31590 /$ ejosat.916024)

ATIF/REFERENCE: Demir, V., Uğur Tona, A. (2021). Debi-Sürek Eğrisi Yardımıyla Taban Akımının Hesaplaması: Samsun Kürtün Irmağı Örneği. Avrupa Bilim ve Teknoloji Dergisi, (24), 502-507.

\section{Öz}

Taban akımı yağış miktarı azaldığında veya kurak zamanlarda yağış olmadığında nehrin kurumasını engeller ve nehirdeki akışın devamlılığını sağlar. Ayrıca taban (baz) akımı çok yağış alan ve kar erimesinin uzun süre devam ettiği drenaj alanlarında taşkınları etkilemektedir. Bu nedenle özellikle taşkın ve kuraklık çalışmalarında baz akımı dikkate alınmalıdır. Bu çalışmada baz akımı, debisürek eğrisi kullanılarak Samsun-Kürtün Irmağı için elde edilmiştir. Kürtün Irmağı için incelenen bu çalışmada zamanın \%95'inde var olan debi taban akımı olarak alınmıştır. Kürtün Irmağı, Yeşilırmak-Kızılırmak nehirlerinin Karadeniz’e çıkış yaptığı ara bölgede yer almaktadır. Nehir içme suyu ve sulama suyu açısından Karadeniz'in en gelişmiş kenti olan Samsun için oldukça önemlidir. Ayrıca nehirde birçok kez taşkın meydana gelmiştir ve bu taşkınlarda birçok alan sular altında kalmıştır. Çalışmada taban akımını belirlemek için ırmak üzerinde yer alan 1964-2020 yılları arası ortalama akım verilerinin gözlemlendiği D14A014 numaralı istasyon kullanılmıştır. Çizilen debi-süreklilik eğrisinden baz akım 4.47 m³/s olarak tespit edilmiş ve yıllara göre taban akımının eğilimi Mann-Kendall trend analizi ile incelenmiştir.

Anahtar Kelimeler: Taban akımı, Debi-sürek eğrisi, Kürtün Irmağı, Samsun, Mann-Kendall.

\section{Calculation of Base-Flow with the Help of Flow-Continuity Curve: The Case Study of Samsun Kürtün River}

\begin{abstract}
The base-flow prevents the river from drying out when the amount of precipitation decreases or there is no precipitation in dry times and ensures the continuity of the flow in the river. Also, the base-flow affects floods in drainage areas where there is a lot of precipitation and snow melting continues for a long time. Therefore, the base flow should be taken into consideration in flood and drought studies. In this study, the base-flow was obtained for the Samsun-Kürtün river located in the central part of the Black Sea Region by using the flow continuity curve. In this study analyzed for Kürtün river, the flow that exists in $95 \%$ of the time is taken as the base flow. The most developed city of the Black Sea in terms of water resources and urbanization, the river is very important for Samsun. In addition, many floods have occurred in the river, and many areas have been flooded in these floods. The station D14A014 whose average stream datas on the river between 1964-2020 were observated was used to determinate the base flow in this study. The base flow was measured as $4.47 \mathrm{~m}^{3} / \mathrm{s}$ by flow continuity curve drawn and the trend of the base flow was examined by years with the Mann-Kendall trend analysis.
\end{abstract}

Keywords: Base-flow, Flow-continuity curve, Kürtün River, Samsun, Mann-Kendall.

\footnotetext{
*Sorumlu Yazar: vahdettin.demir@karatay.edu.tr
} 


\section{Giriş}

$\mathrm{Su}$, dünyada insan hayatının devamı için en önemli yaşam gerekliliklerinin başında gelir. Ancak özellikle son yıllarda küresel iklim değişikliği, hızlı artan nüfus yoğunluğu ve sanayileşmenin etkisinden dolayı tehlikeli bir biçimde azalmaya başlamıştır. Kuşkusuz, suyu önemli kılan bir diğer unsur da suyun ekonomik bir meta haline gelmesi, ağır sanayi ve enerji üretiminde kullanılan temiz bir kaynak olmasıdır. Bu sebeplerden ötürü su kullanımı, maliyeti ve planlaması ile ilgili konular önem arz etmeye başlamıştır. Akarsular su kaynaklarını büyük ölçüde oluşturan sulardır (LeBoutillier, 1993). Su kaynaklarının yönetiminde ve planlanmasında akarsulardaki su miktarının ölçümü ve debilerinin hesaplanması büyük bir öneme sahiptir.

Akarsu debilerinin ölçülmesindeki en iyi yöntem akarsu üzerinde belirli noktalarda akım ölçüm istasyonları kurularak yapılan ölçümlerdir. Fakat akarsu üzerinde her noktada bu istasyonları kurmak çok fazla maliyetlidir. Bundan dolayı, ölçüm yapılan istasyonlardaki akım değerlerinden çeşitli tahmin yöntemleri oluşturularak veya havzanın morfolojik, hidrolojik, jeolojik özelliklerine göre fiziksel modeller ile akım tahmini çalışmaları oluşturulabilmektedir. Akarsu akımının tahmin edilebilmesi için, akarsu akımının bileşenlerinden biri olan ve özellikle su yoğunluğunun en az olduğu kurak mevsimlerde akarsu akımının büyük bir kısmını oluşturan taban akışının belirlenmesi gerekir. Taban akışı, havzaya yağan yağışa, akarsu ağ1 toplam uzunluğuna, drenaj yoğunluğuna, engebeliliğe vb. diğer faktörlere bağlı olduğundan gecikmeli bir akış olarak gerçekleşir.

Taban akışı yaz mevsiminde akarsu akışının büyük bir kısmını, bazı durumlarda ise tamamını karşılamaktadır. Taban akışını bilmek havza ile ilgili planlama ve strateji geliştirmede, su kullanım projelendirmelerinde, su bütçesi hesaplamalarında büyük önem arz etmektedir (Warnick, 1984; Şenocak \& Taşc1, 2020)

Drenaj alanının durumu ve değişen iklim şartları dikkate alındığında taban akışı, yıl boyunca belirli sınırlar arasında değişim gösterir. Çoğunlukla kar erimelerinin ve yağışlarının fazla olduğu bölgelerde kış ve ilkbahar aylarında yüksek, yaz ve sonbahar aylarında düşük olur. Çok fazla yağış alan ve kar erimesinin uzun süre devam ettiği drenaj alanlarında ise taşkınların etkisini artırmaktadır (Özdemir, 1978)

Literatürde ve ülkemiz resmi kurumlarında taban akışı, debisürek (süreklilik) eğrileri yardımıyla hesaplanmaktadır (Demir, 2020; Saka \& Yüksek, 2017; Yanık, 2004). Debi-sürek eğrileri geçmiş bir zaman periyodunda, belirli bir akarsu havzasındaki günlük, aylık veya diğer zaman aralıklı akarsu akımlarının aşıldığı zaman yüzdelerini (\%10, \%20 vb.) göstermektedir (Castellarin et al., 2004; LeBoutillier, 1993; Saka \& Yüksek, 2017). Başka bir ifade ile debi-sürek eğrisi, ele alınan periyottaki belli debi değerlerinin görülme ve aşılma yüzdelerini gösteren birikimli frekans eğrisidir (Searcy, 1959). Sulama, planlama ve tasarımı gibi hidrolojik çalışmalarda ve özellikle, depolamasız hidroelektrik santrallerin planlama ve projelendirme aşamalarında debi-sürek eğrilerinin su temin etme gücü büyük bir öneme sahiptir (Castellarin et al., 2004; LeBoutillier, 1993; Warnick, 1984).
Taban akışı tahmini için daha önceki yıllarda birçok yöntem kullanılmıştır. Bunlardan bazıları örnek olarak aşağıda verilmiştir;

- Grafik yöntemler (Chow et al., 1988; Linsley, R. K., Jr., Kohler, M. A., and Paulhus, 1949),

- Çekilme analizleri (Tallaksen, 1995),

- Hidrokimyasal izleyici tabanlı yöntemler ((Hornberger, G.M., Raffensperger et al., 1998),

- Yumuşatılmış minimumlar yöntemi ve türevleri (Aksoy et al., 2008, 2009; Piggott et al., 2005),

- $\quad$ Dijital filtreleme yöntemleri (Arnold \& Allen, 1999; Lyne \& Hollick, n.d.; Nathan, 1990) ve

- Doğrusal olmayan taban akışı ayırma yöntemleridir ((Aksoy et al., 2011; Wittenberg, 1999, 2003).

- Ayrıca regresyon analizi yaklaşımı ile taban akışını tahmin eden çalışmalar da bulunmaktadır (Zaifoğlu, 2013).

Bu çalışmada Samsun/Kürtün Irmağının baz akımlarını elde etmek için ortalama akım verileri $\left(\mathrm{m}^{3} / \mathrm{s}\right)$ kullanılmıştır. Akım verilerinin periyodu 1964-2020 yıllarını kapsamaktadır. İlgili yıllar arasında baz akımı, çizilen debi-sürek eğrisi (zamanın \%95'inde var olan) yardımıyla elde edilmiştir. Ayrıca bu çalışma ile baz akımının yıllara göre değişimi literatürden farklı olarak Mann (1945)-Kendall (1975) trend yöntemi kullanılarak incelenmiştir.

\section{Materyal ve Metot}

\section{1. Çalışma Alanı}

Orta Karadeniz Bölümü'nde yer alan Samsun şehri, Türkiye'nin en kalabalık on altıncı, Karadeniz bölgesinin ise en kalabalık şehridir. Kuzeyinde Karadeniz, doğusunda Ordu, güneyinde Tokat ve Amasya, batısında ise Çorum ve Sinop illeri yer almaktadır. Çalışma alanı Şekil 1'de yer almaktadır.

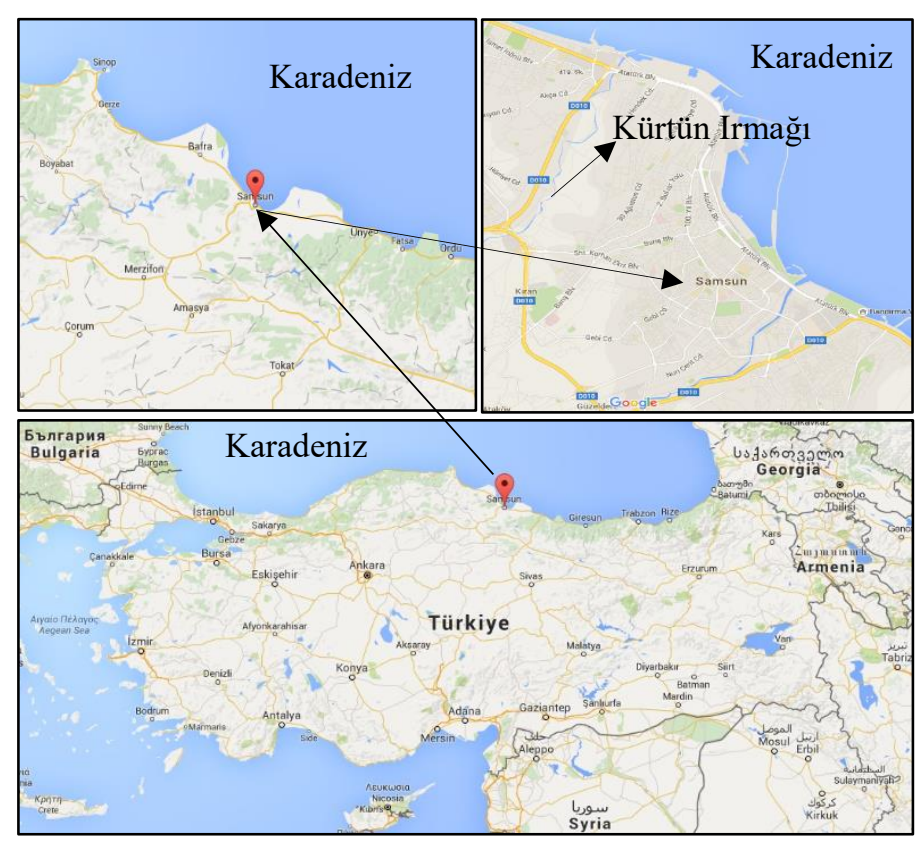

Şekil 1. Çalışma alanı

Samsun'un Kavak ilçesinin sınırlarından başlayan (1100 metre rakımda) Kürtün Irmağı, Samsun il merkezinden Karadeniz'e dökülmektedir. $259 \mathrm{~km}^{2}$ yağış alanına sahip ırmağın, ana akarsu boyu $47 \mathrm{~km}$ 'dir ve yıllık ortalama akımı $47 \mathrm{hm}^{3}$ 'dür (Bakanlık, 2020). 


\subsection{Materyal}

Bu çalışmada Samsun ili Kürtün Irmağı üzerinde yer alan (Türkiye'nin 14 No'lu Yeşilırmak Havzası'nda yer alan ve D14A014 No'lu Samsun-Ankara karayolunun 11. kilometresindeki Çağlayan Mevkiinde) akım gözlem istasyonunun (koordinatları: 41 $17^{\prime} 10^{\prime \prime} \mathrm{D}, 36^{\circ} 11^{\prime} 43$ 'K, Rakım $140 \mathrm{~m})$ günlük, aylık ve yıllık ortalama akım verileri $\left(\mathrm{m}^{3} / \mathrm{s}\right)$ kullanılmıştır. İlgili veriler Devlet Su İşleri Genel Müdürlüğü (DSI)'den temin edilmiştir. Kullanılan veriler 1964-2020 (55 yıl) yıllarını kapsamaktadır. Aylık ortalama akım verilerine ait temel istatistiki bilgiler Tablo 1'de yer almaktadır. Ayrıca verilere ait gidiş grafiği Şekil 2'de yer almaktadır.

Tablo 1. Kürtün istasyonu aylık ortalama akım verilerine $\left(\mathrm{m}^{3} / \mathrm{s}\right)$ ait temel istatistiki bilgiler

\begin{tabular}{ccccccc}
\hline Aylar & $\begin{array}{c}\text { Ortalama } \\
\text { Akım }\end{array}$ & $\begin{array}{c}\text { Maksimum } \\
\text { Akım }\end{array}$ & $\begin{array}{c}\text { Minimum } \\
\text { Akım }\end{array}$ & $\begin{array}{c}\text { Standart } \\
\text { Sapma }\end{array}$ & $\begin{array}{c}\text { Çarpıklık } \\
\text { Katsayısı }\end{array}$ & $\begin{array}{c}\text { Basıklık } \\
\text { Katsayısı }\end{array}$ \\
\hline Eki & 0.53 & 8.20 & 0.03 & 1.12 & 6.11 & 41.24 \\
Kas & 0.73 & 6.93 & 0.09 & 1.02 & 4.52 & 25.21 \\
Ara & 1.14 & 4.44 & 0.26 & 0.89 & 1.45 & 2.35 \\
Oca & 1.60 & 4.13 & 0.31 & 1.12 & 0.97 & -0.29 \\
Şub & 2.05 & 4.85 & 0.20 & 1.05 & 0.51 & 0.31 \\
Mar & 3.31 & 7.36 & 0.51 & 1.70 & 0.38 & -0.51 \\
Nis & 2.93 & 8.65 & 0.37 & 1.80 & 1.05 & 1.15 \\
May & 2.05 & 6.48 & 0.31 & 1.36 & 1.45 & 1.88 \\
Haz & 1.10 & 3.98 & 0.22 & 0.72 & 1.91 & 4.72 \\
Tem & 0.66 & 3.88 & 0.06 & 0.67 & 3.38 & 13.55 \\
Ağu & 0.39 & 2.68 & 0.04 & 0.43 & 3.42 & 14.62 \\
Eyl & 0.36 & 2.20 & 0.04 & 0.40 & 3.51 & 13.74 \\
\hline
\end{tabular}

Tablo 1 incelendiğinde, en düşük akımların $0.03 \mathrm{~m}^{3} / \mathrm{s}$ ile ekim aylarında görülmesine rağmen en düşük ortalama akımlar ağustos $\left(0.39 \mathrm{~m}^{3} / \mathrm{s}\right)$ ve eylül $\left(0.36 \mathrm{~m}^{3} / \mathrm{s}\right)$ aylarında görülmektedir. Maksimum akım verileri de göz önüne alındığında ırmağın en kurak ayları ağustos-eylül aylarıdır. Irmağın en yüksek akımlarının görüldüğü ay ise nisan aylarıdır. Benzer şekilde en fazla standart sapmanın görüldüğü ay nisan ayıdır. Nisan ayında görülen bu durum yağış rejiminden kaynaklanmaktadır. Irmakta gözlemlenen yıllık ortalama akım değeri $1.40 \mathrm{~m}^{3} / \mathrm{s}$ 'dir. Verilerin çarpıklık katsayıları incelendiğinde, tüm aylarda dağılımın normal dağılıma göre sağa çarpık (çarpıklık katsayısı >0) olduğu görülmektedir. Benzer şekilde basıklık katsayısı incelendiğinde aralık-mayıs aylarında normal dağılıma göre basık, diğer aylarda sivri bir dağılım görülmektedir.

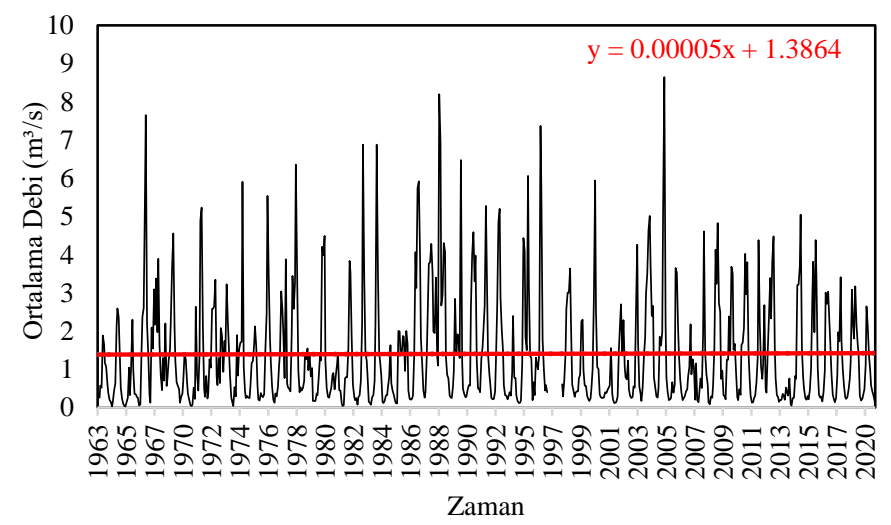

Şekil 2. Aylık ortalama akım verilerine ait gidiş grafiği
Şekil 2 incelendiğinde, ortalama akım verilerinin lineer grafiği artan yöndedir. Ayrıca 1997 yılına ait akım kayıtları bulunmadığı için çalışmada 1997 yılına ait baz akım hesaplamaları yapılamamıştır.

\subsection{Metot}

\subsubsection{Debi-Sürek Ĕgrisi ve Taban Akım Hesabı}

$\mathrm{Bu}$ çalışmada taban akımı, debi-sürek eğrileri kullanılarak elde edilmiştir. Debi sürek eğrisi, seçilen bir zaman birimindeki debi miktarının zamanla nasıl değiştiğini gösteren bir grafiktir (Saka \& Yüksek, 2017). Debi-sürek eğrisinden faydalanılarak, debinin belli bir değere eşit veya ondan büyük olduğu zaman yüzdesi hesaplanarak, düşey eksene debiler, yatay eksene zaman yüzdeleri yerleştirilerek debi-sürek eğrisi elde edilmektedir (Bayazıt, 1999; Bahattin Yanık \& Avcı, 2005)

Ortalama akımların debi-sürek eğrisi, akım-güven ilişkisine dayanır. Debi-sürek eğrileri elde edilen akım verilerinin küçükten büyüğe doğru sıralanmasıyla yapay sıralı hale getirilir. Yapay siralı akım verilerinin mertebesi (m) belirlenir. Mertebe yapay sıralı akım verilerinin en küçüğüne 1 değeri verilmek üzere, akım verisi sayısı kadar devam ettirilir. Ardından veri sayısı (N) ve mertebe (m)'ye bağlı olarak güven ( $\dot{\mathrm{g}})$ değerleri yüzdesel olarak hesaplanır. Her bir mertebe için güven değeri Denklem 1 yardımiyla elde edir (Demir, 2020; Şen, 2009).

$$
\dot{g}=\frac{m}{N+1}
$$

Güven değerleri her bir mertebe için elde edildikten sonra akım-güven veya akım-sürek grafiği çizilir (Saka \& Yüksek, 2017). Çizilen grafik üzerinden aşılma ihtimali yüksek olan (\%95) küçük debiler taban (baz) akımını temsil etmektedir (Yanık, 2004). Ayrıca baz akım hesabında günlük ortalama akımlar kullanılmalıdır (Saka \& Yüksek, 2017; Saplıŏlu \& Mesut, 2010). $\mathrm{Bu}$ nedenle günlük ortalama akımlar kullanılarak yıllara göre baz akım değerleri elde edilmiştir.

\subsubsection{Mann-Kendall (MK)}

Mann-Kendall istatistiği " $S$ " hesaplandıktan sonra aşağıda yer alan denklemler kullanılarak MK "Z" değeri hesaplanır hesaplanır (Denklem 2-5). Hesaplanan Z değeri de belirlenen olasılık anlamlılık düzeylerine göre normal dağılım çizelgesindeki standart Z değerleriyle karşılaştırılır (Mann, 1945; Kendall, 1975).

MK testi için ilk olarak " $\mathrm{S}$ " yani MK test istatistiği toplam değeri hesaplanmalıdır. $\mathrm{Bu}$ amaçla veri sütunları ilk ölçüm tarihinden son ölçüm tarihine sıralanmalıdır (i=1,..,N-1'e kadar sıralanmış xi veri sütunu ile $\mathrm{j}=\mathrm{i}+1, \ldots, \mathrm{N}$ 'e kadar sıralanmış $x \mathrm{j}$ veri sütunlarını oluşturacak şekilde). Ardından, xi veri sütunu başlangıç olarak kullanılır ve diğer sıralanmış xj ile Denklem 2'deki signum fonksiyonu kullanılarak Denklem 3'teki "S" değeri hesaplanır. $\mathrm{Bu}$ işlemler sonucunda tüm veri çiftlerinin farkı (xj-xi) ile pozitif ve negatif değerlerin sayısının toplamı bulunmuş olur (Demir \& Keskin, 2020; Yagbasan, Demir, \& Yazicigil, 2020).

$$
\operatorname{sgn}\left(x_{j}-x_{i}\right)=\left\{\begin{array}{ccc}
1 ; & \text { Ĕ̆ } & x_{j}>x_{i} \\
0 ; & \text { Ĕger } & x_{j}=x_{i} \\
-1 ; & \text { Ĕger } & x_{j}<x_{i}
\end{array}\right.
$$




$$
S=\sum_{i=1}^{N-1} \sum_{j=i+1}^{N} \operatorname{sgn}\left(x_{j}-x_{i}\right)
$$

Veri sayısı "N" olmak üzere $\mathrm{N}>10$ ise seriler için varyans hesabı yapılır (Denklem 4) ve yaklaşık olarak normal dağılıma uygun olduğu öngörülür. Varyans hesaplandıktan sonra, Denklem 5 'te "S" sinırlarına göre güven aralı̆̆ı değeri "Z" hesaplanır. Hesaplanan $\mathrm{Z}$ değeri, belirlenen olasılık düzeylerine karşılık gelen normal dağılım tablosundaki standart $Z$ değerleriyle karşılaştırılır (Yu et al., 1993).

$$
\operatorname{Var}(S)=\frac{N(N-1)(2 N+5)-\sum_{i=1}^{P^{\prime}} t_{i}\left(t_{i}-1\right)\left(2 t_{i}+5\right)}{18}
$$

Denklem 4'te P'; serideki bağlı grupların sayıları, ti; i uzunluğundaki bir seride bağlı gözlemlerin sayısını ifade etmektedir.

$$
Z=\left\{\begin{array}{ccc}
\frac{S-1}{\sqrt{\operatorname{Var}(S)} ;} ; & \text { Ĕger } & S>0 \\
0 ; & \text { Ĕger } & S=0 \\
\frac{S+1}{\sqrt{\operatorname{Var}(S)} ;} ; & \text { Eğer } & S<0
\end{array}\right.
$$

Trendin olup olmadığı ise Normal dağılımın $Z$ değerleri ile belirlenir. Denklem 5 yardımıyla hesaplanan $Z$ değeri, $\alpha$ anlamlılık düzeyine karşı gelen normal dağılımın $Z_{1-\alpha / 2}$ değerinden büyük olduğu durumlarda sıfır hipotezi $\left(\mathrm{H}_{0}\right)$ kabul edilmemektedir. Başka bir ifade ile, zaman serisinde bir eğilimin söz konusu olduğu sonucuna varılmaktadır. Benzer şekilde $\mathrm{Z}$ değeri, dağılım çizelgesindeki $Z_{1-\alpha / 2}$ değerinden küçük olduğu durumlarda $\left(\mathrm{H}_{0}\right)$ kabul edilmektedir ve zaman serisinde istatistiksel olarak anlamlı bir eğilimin olmadığı anlaşılmaktadır. (S) değeri pozitif hesaplanırsa, incelenen olayda artan yönde, negatif hesaplanırsa azalan yönde bir eğilim olduğu sonucuna varılır (Kendall, 1975; Mann, 1945).

\section{Araștırma Sonuçları ve Tartışma}

\subsection{Kürtün Irmağı Baz Akım Değerlerinin Elde Edilmesi}

Bu çalışmada, Kürtün Irmağı'na ait günlük ortalama akımların debi-sürek eğrileri çizilimiş ve zamanın \%95'inde meydana gelen akım, baz akım olarak alınmıştır (Şekil 4). İlgili işlemler 1964-2020 yılları arasında tekrarlanarak yıllara göre baz akım değerleri (Tablo 2) ve değişim grafiği elde edilmiştir (Şekil 5). Örnek olarak 2016 yılına ait günlük ortalama debi-gidiş eğrisi Şekil 3 'te yer almaktadır.

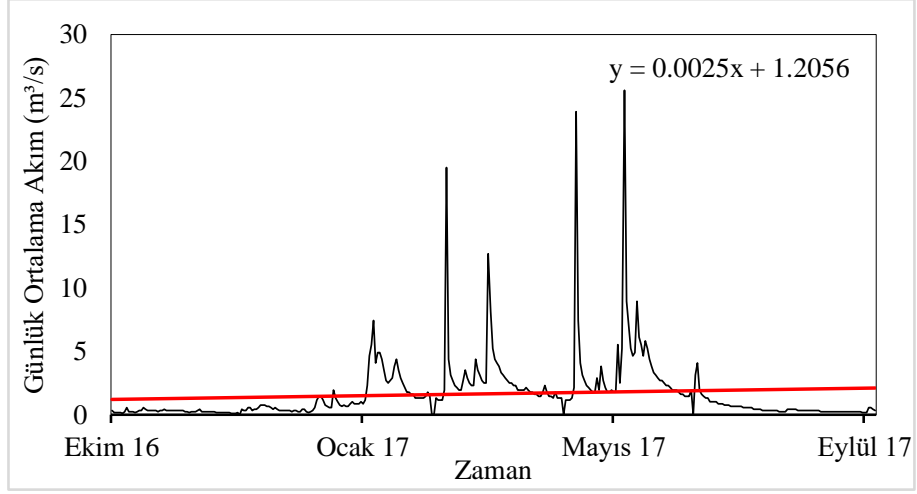

Şekil 3. Günlük ortalama akım verilerine ait gidiş grafiği e-ISSN: 2148-2683
Akım verileri su yıllığı Ekim ayında başlar ve Eylül ayında son bulur. Kürtün Irmağı'na ait debi-sürek eğrisi ise Şekil 4'te yer almaktadır.

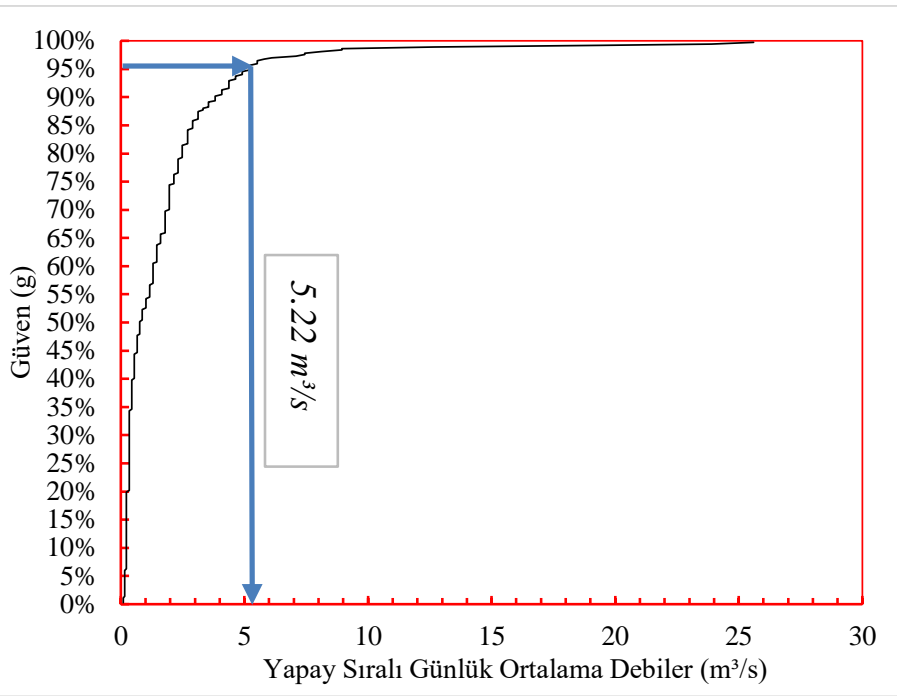

Şekil 4. Günlük ortalama akım verilerine ait debi-sürek eğrisi

Şekil 4'te zamanın \%95'inde var olan debi okunmuş ve 5.22 $\mathrm{m}^{3} / \mathrm{s}$ olarak belirlenmiştir. Diğer yıllara ait baz akım değerleri Tablo 2'de yer almaktadır.

Tablo 2. Baz akım değerleri $\left(\mathrm{m}^{3} / \mathrm{s}\right)$

\begin{tabular}{cccccc}
\hline Yıl & $\begin{array}{c}\text { Baz } \\
\text { Akım }\end{array}$ & Yıl & $\begin{array}{c}\text { Baz } \\
\text { Akım }\end{array}$ & Yıl & $\begin{array}{c}\text { Baz } \\
\text { Akım }\end{array}$ \\
\hline $\mathbf{1 9 6 4}$ & 1.75 & $\mathbf{1 9 8 3}$ & 6.7 & $\mathbf{2 0 0 2}$ & 3.9 \\
$\mathbf{1 9 6 5}$ & 3.3 & $\mathbf{1 9 8 4}$ & 6.7 & $\mathbf{2 0 0 3}$ & 3.7 \\
$\mathbf{1 9 6 6}$ & 2.4 & $\mathbf{1 9 8 5}$ & 1.4 & $\mathbf{2 0 0 4}$ & 7.0 \\
$\mathbf{1 9 6 7}$ & 6.6 & $\mathbf{1 9 8 6}$ & 3.6 & $\mathbf{2 0 0 5}$ & 8.3 \\
$\mathbf{1 9 6 8}$ & 4.6 & $\mathbf{1 9 8 7}$ & 7.7 & $\mathbf{2 0 0 6}$ & 4.63 \\
$\mathbf{1 9 6 9}$ & 4.6 & $\mathbf{1 9 8 8}$ & 5.9 & $\mathbf{2 0 0 7}$ & 2.23 \\
$\mathbf{1 9 7 0}$ & 1.55 & $\mathbf{1 9 8 9}$ & 9.2 & $\mathbf{2 0 0 8}$ & 3.45 \\
$\mathbf{1 9 7 1}$ & 6.9 & $\mathbf{1 9 9 0}$ & 5.3 & $\mathbf{2 0 0 9}$ & 5.6 \\
$\mathbf{1 9 7 2}$ & 4.9 & $\mathbf{1 9 9 1}$ & 5.3 & $\mathbf{2 0 1 0}$ & 4.63 \\
$\mathbf{1 9 7 3}$ & 4.0 & $\mathbf{1 9 9 2}$ & 5.0 & $\mathbf{2 0 1 1}$ & 4.64 \\
$\mathbf{1 9 7 4}$ & 3.1 & $\mathbf{1 9 9 3}$ & 6.0 & $\mathbf{2 0 1 2}$ & 4.64 \\
$\mathbf{1 9 7 5}$ & 2.3 & $\mathbf{1 9 9 4}$ & 2.2 & $\mathbf{2 0 1 3}$ & 4.64 \\
$\mathbf{1 9 7 6}$ & 5.4 & $\mathbf{1 9 9 5}$ & 7.0 & $\mathbf{2 0 1 4}$ & 0.87 \\
$\mathbf{1 9 7 7}$ & 3.5 & $\mathbf{1 9 9 6}$ & 7.3 & $\mathbf{2 0 1 5}$ & 5.22 \\
$\mathbf{1 9 7 8}$ & 5.5 & $\mathbf{1 9 9 7}$ & --- & $\mathbf{2 0 1 6}$ & 5.22 \\
$\mathbf{1 9 7 9}$ & 2.1 & $\mathbf{1 9 9 8}$ & 5.4 & $\mathbf{2 0 1 7}$ & 4.09 \\
$\mathbf{1 9 8 0}$ & 5.3 & $\mathbf{1 9 9 9}$ & 2.97 & $\mathbf{2 0 1 8}$ & 3.33 \\
$\mathbf{1 9 8 1}$ & 1.9 & $\mathbf{2 0 0 0}$ & 5.42 & $\mathbf{2 0 1 9}$ & 3.54 \\
$\mathbf{1 9 8 2}$ & 4.2 & $\mathbf{2 0 0 1}$ & 1.0 & $\mathbf{2 0 2 0}$ & 2.70 \\
\hline
\end{tabular}

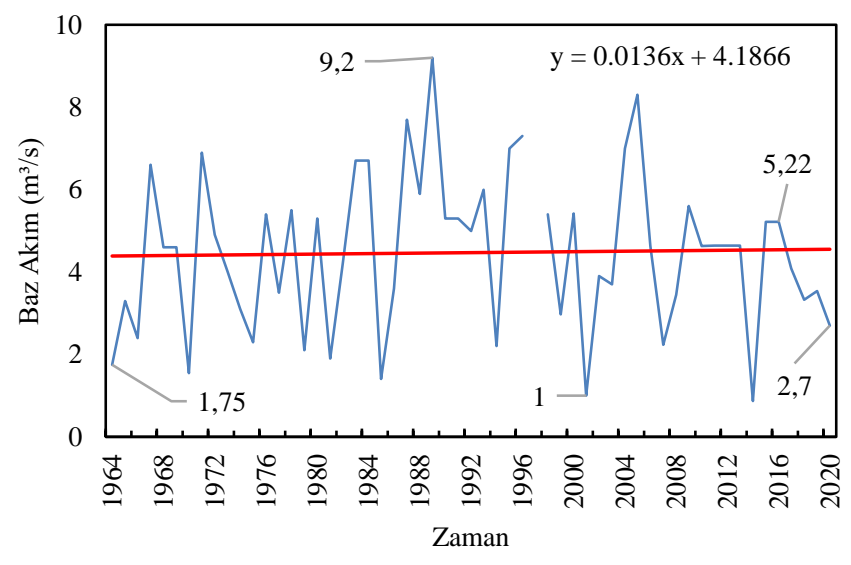

Şekil 5. Günlük ortalama akım verileri ile elde edilmiş baz akımlarına ait gidiş grafiği 


\subsection{Baz Akımlarının Trend Analizi}

Elde edilen baz akım değerlerinin eğilimini belirlemek için Mann-Kendall trend testi kullanılmıştır. Analizler güven aralığının \%95'lik kısmında gerçekleşmiştir. Tablo 2'de yer alan verilerin $M K Z$ hesap değeri $\mathbf{0 . 1 9 0}$ 'dır. Hesap değerinin işareti pozitif olduğu için artan bir eğilim söz konusudur fakat bu değer sınır değer olan \pm 1.96 'dan düşük olması nedeniyle istatistiksel olarak anlamsızdır.

\section{Sonuç}

Bu çalışmada, Samsun ili Kürtün Irmağı'nın 1964-2020 (55 yıl) baz akım değerleri debi-sürek eğrisi kullanılarak yıllara göre elde edilmiştir. Elde edilen debi değerlerinin eğilimini test etmek için MK trend analizi kullanılmıştır. Sonuçlar incelendiğinde uzun dönem taban akım değerinin $4.47 \mathrm{~m}^{3} / \mathrm{s}$, en düşük taban akımının $1 \mathrm{~m}^{3} / \mathrm{s}$ (2001 yılı) ve en yüksek taban akım değerinin 9.2 $\mathrm{m}^{3} / \mathrm{s}$ (1989 yılı) olduğu tespit edilmiştir. Akım verilerinin ve baz akımların lineer gidiş grafiği artan yöndedir (Şekil 2, 3 ve 5). MK trend analizine göre ise taban akımları artan bir eğim gösterse de bu eğilim istatistiksel olarak güven aralığında kaldığı için anlamlı olmamaktadır.

\section{Teşekkür}

Yazarlar akım verilerinin temin edilmesinde yardımlarından dolayı DSİ 7. Bölge Müdürlüğü’ne teşekkür etmektedir.

\section{Kaynakça}

Aksoy, H., Kurt, I., \& Eris, E. (2009). Filtered smoothed minima baseflow separation method. Journal of Hydrology, 372(14), 94-101. https://doi.org/10.1016/j.jhydrol.2009.03.037

Aksoy, H., Unal, N. E., \& Pektas, A. O. (2008). Smoothed minima baseflow separation tool for perennial and. 4476(June), 4467-4476. https://doi.org/10.1002/hyp

Aksoy, H., Wittenberg, H., Aksoy, H., \& Wittenberg, H. (2011). Nonlinear baseflow recession analysis in watersheds with intermittent streamflow Nonlinear baseflow recession analysis in watersheds with intermittent streamflow. 6667. https://doi.org/10.1080/02626667.2011.553614

Arnold, J. G., \& Allen, P. M. (1999). Automated Methods For Estımatıng Baseflow And Ground Water Recharge From Streamflow Records1. JAWRA Journal of the American Water Resources Association, 35(2), 411-424. https://doi.org/https://doi.org/10.1111/j.17521688.1999.tb03599.x

Bakanlık. (2020). Yeşilırmak Havası Taşkın Yönetim Planı. Orman ve $\mathrm{Su}$ İşleri Bakanlığı, Su Yönetimi Genel Müdürlüğü.

https://www.tarimorman.gov.tr/SYGM/Belgeler/Taşkın Yönetim Planları/1) Yesılırmak Havzası Taşkın Yönetım PlanI.pdf

Bayazıt, M. (1999). Hidroloji. İTÜ İnşaat Fakültesi Matbaası.

Castellarin, A., Galeati, G., Brandimarte, L., Montanari, A., \& Brath, A. (2004). Regional flow-duration curves: Reliability for ungauged basins. Advances in Water Resources, 27(10), 953-965. https://doi.org/10.1016/j.advwatres.2004.08.005

Chow, V. T., Maidement, D. R., \& Mays, L. W. (1988). Applied Hydrology. Water Resources and Environmental Engineering.

Demir, V. (2020). Samsun Mert havzasinda bir ve iki boyutlu modeller ile taşkın alanlarının belirlenmesi. Ondokuz Mayıs

e-ISSN: 2148-2683
Üniversitesi, Lisansüstü Eğitim Enstitüsü.

Demir, V., \& Keskin, A. Ü. (2020). Water level change of lakes and sinkholes in Central Turkey under anthropogenic effects. Theoretical and Applied Climatology, 142(3-4), 929-943. https://doi.org/10.1007/s00704-020-03347-5

Hornberger, G.M., Raffensperger, J. P., Wiberg, P. L., \& Eshleman, K. N. (1998). Elements of physical hydrology. The Johns Hopkins University Press, Baltimore, 302pp.

Kendall, M. G. (1975). Rank Correlation Methods. Chtirles Griffin.

LeBoutillier, D. W. (1993). A stochastic model of flow duration curves. Water Resources Research, 29(10), 3535-3541. https://doi.org/10.1029/2003WR002524

Linsley, R. K., Jr., Kohler, M. A., and Paulhus, J. L. H. (1949). Applied Hydrology. McGraw-Hill: New York.

Lyne, V. D., \& Hollick, M. (n.d.). Stochastic time-variable rainfall runoff modeling,. Hydro. and Water Resources Symposium Institution of Engineers, 89-92.

Mann H B. (1945). "Non-parametric tests against trend." Econometrica, 13(3), 245-259.

Nathan, R. J. (1990). Evaluation of Automated Techniques for Base Flow and Recession Analyses. 26(7), 1465-1473.

Özdemir, H. (1978). Uygulamalı Taşkın Hidrolojisi. DSI Matbaas1, Ankara.

Piggott, A. R., Moin, S., \& Southam, C. (2005). A revised approach to the UKIH method for the calculation of baseflow / Une approche améliorée de la méthode de 1 ' UKIH pour le calcul de 1' écoulement de base A revised approach to the UKIH method for the calculation of baseflow. Hydrological Sciences Journal ISSN:, 50(5), 911-920. https://doi.org/https://doi.org/10.1623/hysj.2005.50.5.911

Saka, F., \& Yüksek, Ö. (2017). Regionalisation of discharges having certain exceedance probabilities and Eastern Black Sea Basin sample. Gazi Üniversitesi Mühendislik-Mimarlık Fakültesi Dergisi, 32(2), 335-342. https://doi.org/10.17341/gazimmfd.322154

Saplığlu, K., \& Mesut, Ç. (2010). Taban Akışı Ayrımı İçin Bir Yöntem. E-Journal of New World Sciences Academy, 5(4), 580-589.

Searcy, J. K. (1959). Flow-duration curves. https://doi.org/10.3133/wsp1542A

Şen, Z. (2009). Taşkın Afet ve Modern Hesaplama Yöntemleri. Su Vakfi Yayınları.

Şenocak, S., \& Taşcı, S. (2020). Çoruh Havzası Taban Akışının İngiliz Hidroloji Enstitüsü Yuvarlatılmış Minimumlar Yöntemi ile Belirlenmesi. Erzincan Üniversitesi Fen Bilimleri Enstitüsü Dergisi, 13(1), 123-133. https://doi.org/10.18185/erzifbed.655870

Tallaksen, L. M. (1995). A review of baseflow recession analysis. Journal of Hydrology, 165(1-4), 349-370. https://doi.org/10.1016/0022-1694(94)02540-R

Warnick, C. C. (1984). Hydropower Engineering. Prentice-Hall Inc., Englewood Cliffs, New Jersey.

Wittenberg, H. (1999). Base ${ }^{-}$ow recession and recharge as nonlinear storage processes Abstract: 726(August 1998), 715-726.

Wittenberg, H. (2003). Effects of season and man-made changes on baseflow and flow recession: case studies. 2123(April 2001), 2113-2123. https://doi.org/10.1002/hyp.1324

Yagbasan, O., Demir, V., \& Yazicigil, H. (2020). Trend Analyses of Meteorological Variables and Lake Levels for Two Shallow Lakes in Central Turkey. Water, 12(2), 414. https://doi.org/10.3390/w12020414 
Yanık, B. (2004). Doğal aklşlı hidroelektrik potansiyelin belirlenmesinde bölgesel analiz yaklaşımı. İstanbul Teknik Üniversitesi, Fen Bilimleri Enstitüsü.

Yanık, Bahattin, \& Avcı, İ. (2005). Bölgesel debi süreklilik eğrilerinin elde edilmesi. Itüdergisi, 4(5), 19-30.

Yu, Y.-S., Zou, S., \& Whittemore, D. (1993). Non-parametric trend analysis of water quality data of rivers in Kansas. Journal of Hydrology, 150(1), 61-80. https://doi.org/10.1016/0022-1694(93)90156-4

Zaifoğlu, H. (2013). Fırat Akarsu Havzası İçin Topoğrafik ve Hidrometeorolojik Veriye Dayanan Taban Akışı Ayırma Modeli. Fen Bilimleri Enstitüsü İTÜ İnşaat Fakültesi, İnşaat Mühendisliği Bölümü. 